$R_{\text {ESearch }} P_{\text {POR }}$ FOOD SCIENCE RESEARCH JOURNAL
ISSN-0976-1276 - Visit us : www.researchjournal.co.in Volume $11 \mid$ Issue 2 | October, $2020 \mid 151-157$ DOI : $10.15740 / \mathrm{HAS} / \mathrm{FSRJ} / 11.1 / 151-157$

\title{
Studies on textural and sensory quality attributes of biscuits using wheat, sorghum and groundnut blend flour
}

\author{
Rohit Kumar Maurya, Devendra Kumar, Devendra Singh and Vipin Kumar Verma
}

Experiments were conducted to evaluate quality attributes of biscuits using wheat, sorghum and groundnut blend flour. Study was also conducted to see the effect of blend flours treatments on textural characteristic and sensory evaluation. Flours blend were prepared with various combination of wheat, sorghum and groundnut as $\mathrm{W}_{80}: \mathrm{S}_{15}: \mathrm{G}_{05}\left(\mathrm{~T}_{1}\right), \mathrm{W}_{70}: \mathrm{S}_{20}: \mathrm{G}_{10}$ $\left(\mathrm{T}_{2}\right)$ and $\mathrm{W}_{60}: \mathrm{S}_{25}: \mathrm{G}_{15}\left(\mathrm{~T}_{3}\right)$. Textural characteristics viz., fracturability, hardness, cohesiveness, adhesiveness through texture analyzer. The sensory characteristics viz., colour, odor, flavour, taste, texture and overall acceptability were evaluated for fresh, 30, 60 and 90 days of storage period. The maximum hardness was found in sample prepared for treatment $T_{2}(2752.70 \mathrm{~g})$, whereas higher cohesiveness value was obtained in sample of treatment $T_{1}(1.67)$. The adhesiveness and springiness were obtained maximum in sample of treatment $T_{3}(8.47$ g.s $)$ and treatment $T_{2}(2.09 \mathrm{~mm})$, respectively. The gumminess and chewiness value were found highest in sample of treatment $T_{2}(4349.26 \mathrm{~g})$ and treatment $\mathrm{T}_{2}$ (9056.48 g.mm), respectively. Sensory characteristics as colour, odor, flavour, taste and overall acceptability were scored highest rating in $\mathrm{T}_{2}$ treatment as compared to $\mathrm{T}_{1}$ and $\mathrm{T}_{3}$ treatments. Sensory score was decreased with increase of storage period in all treatments. Fresh biscuit samples prepared with wheat $70 \%+$ sorghum $20 \%+$ groundnut $10 \%$ rated highest score (7.8) than other treatments. The treatment $\left(\mathrm{T}_{2}\right)$ gave better product in view of colour, odor, flavour, taste and overall acceptability as well as textural quality attributes.

Key Words : Biscuit, Blend flour, Textural, Sensory

How to cite this article : Maurya, Rohit Kumar, Kumar, Devendra, Singh, Devendra and Verma, Vipin Kumar (2020). Studies on textural and sensory quality attributes of biscuits using wheat, sorghum and groundnut blend flour. Food Sci. Res. J., 11(2): 151-157, DOI : 10.15740/HAS/FSRJ/11.2/151-157.Copyright@ 2020: Hind Agri-Horticultural Society.

Rohit Kumar Maurya, Dr. Bhim Rao Ambedkar College of Agricultural Engineering and Technology (C.S.A.U.A. and T.), Etawah (U.P.) India

Email: rohitmaurya3131@gmail.com

Associate Authors' :

Devendra Kumar, Devendra Singh and Vipin Kumar Verma, Dr. Bhim Rao Ambedkar College of Agricultural Engineering and Technology (C.S.A.U.A. and T.), Etawah (U.P.) India Email:devendrachaturvedi2008@gmail.com; dsinghcsau@gmail.com; vipincaet79@gmail.com 